www.nature.com/jhg

\title{
Climatic influence on the reproductive characteristics of Japanese males
}

\author{
Yutaka Nakahori $^{1,2}$, Youichi Sato ${ }^{1}$, Ashraf A Ewis ${ }^{1}$, Teruaki Iwamoto ${ }^{2,3}$, Toshikatsu Shinka ${ }^{1,2}$, Shiari Nozawa ${ }^{2,3}$, \\ Miki Yoshiike ${ }^{2,3}$, Xin-Jun Yang ${ }^{1,2}$, Masako Sei ${ }^{1}$, Mikio Namiki ${ }^{4}$, Eitetsu Kou ${ }^{4}$, Naoki Ito ${ }^{5}$, Kiyoshi Komatsu ${ }^{6}$, \\ Kiyomi Matsumiya ${ }^{7}$ and Yasuo Nakagome ${ }^{8}$
}

We previously performed a survey of the sperm characteristics of the partners of pregnant women in four cities in Japan. In the present study, we analyzed the sperm characteristics of these subjects and the correlations between these sperm characteristics and climatic changes or $Y$ chromosome haplogroups. Our results showed that more haplogroup D2a1 males than 02b1 males were born in the first half of the year (January to June), whereas more 02b1 males were born in the last half of the year (July to December) $(P<0.05)$. This was agreed and correlated with the seasonal variations in their mean sperm concentrations. The haplogroup C, $D^{*}$ and D2a1 males displayed lower sperm concentrations from March to May, followed by an increase in their sperm concentrations starting in June or July, while the $02 \mathrm{~b} 1$ males displayed higher sperm concentrations in the first half of the year followed by a sudden decrease from July to August $(P<0.05)$. We hypothesize that the Japanese climate has different effects on the sperm characteristics and reproductive seasonality of males from different lineages; and therefore, has influenced the modern population of Japan.

Journal of Human Genetics (2012) 57, 375-378; doi:10.1038/jhg.2012.38; published online 26 April 2012

Keywords: Japanese population; reproductive seasonality; sperm characteristics; Y chromosome haplogroup

\section{INTRODUCTION}

Using Y chromosome DNA polymorphisms, molecular and human genetic studies of the Japanese population have revealed that the Japanese belong to several Y chromosome lineages that are defined as Y chromosome haplogroups. According to the haplogrouping and nomenclature system of the Y Chromosome Consortium (YCC), ${ }^{1}$ Japanese males mainly belong to the haplogroups $\mathrm{C}, \mathrm{D}^{*}, \mathrm{D} 2 \mathrm{a} 1, \mathrm{O}_{2} \mathrm{~b}^{\star}, \mathrm{O} 2 \mathrm{~b} 1, \mathrm{O}^{*}$ and O3a3c. Haplogroup $\mathrm{C}$ is prevalent in various areas such as Australia, Polynesia, northeastern and northwestern China, Mongolia, Siberia, and others. ${ }^{2}$ Haplogroup D is limited to Tibet and Japan and displays the highest frequency among the Ainu and Ryukyuans in Japan. ${ }^{3-5}$ $\mathrm{O}^{*}$ and $\mathrm{O} 3 \mathrm{a} 3 \mathrm{c}$ are found in various East Asian populations, ${ }^{6}$ while $\mathrm{O} 2 \mathrm{~b} 1$ and its ancestral type $\mathrm{O}_{2} \mathrm{~b}^{\star}$ are mostly limited to Korea ${ }^{7}$ and Japan. ${ }^{8,9}$

The phenotypic variations among males belonging to these different Y chromosome lineages have been investigated. In 1999, we hypothesized that males from different $\mathrm{Y}$ chromosome lineages might display different spermatogenic abilities, and we subsequently investigated and proved this hypothesis in a study of Japanese males. ${ }^{10}$ After our report, several researchers have presented similar findings from different populations ${ }^{11}$ and confirmed that males from different Y chromosome haplogroups have different sperm characteristics.

In another survey, which we performed between 1997 and 2002, we investigated the sperm characteristics of the partners of pregnant women in four cities in Japan (from north to south: Sapporo, Kanazawa, Osaka and Fukuoka). The participants provided blood and semen samples and answered a questionnaire, ${ }^{12}$ and we studied the reproductive function statuses of these fertile Japanese men as part of an international collaborative project studying the partners of pregnant women.

In the current study, we used DNA samples from the abovementioned Japanese male partners of pregnant women in order to type their $\mathrm{Y}$ chromosome polymorphisms, and investigate the hypothesis that Japanese men from different Y chromosome lineages display seasonal variations in their sperm concentrations (or 'quality'). Such differences could have affected the reproductive abilities of these lineages, and hence, the modern population of Japan.

\footnotetext{
${ }^{1}$ Department of Human Genetics and Public Health, Graduate School of Medical Science, University of Tokushima, Tokushima, Japan; ${ }^{2}$ Core Research for Evolutional Science and Technology, Japan Science and Technology Corporation, Saitama, Japan; ${ }^{3}$ Department of Urology, St Marianna University School of Medicine, Kawasaki, Japan; ${ }^{4}$ Department of Integrative Cancer Therapy and Urology, Graduate School of Medical Science, Kanazawa University, Ishikawa, Japan; ${ }^{5}$ Department of Urology, Sapporo Medical University School of Medicine, Sapporo, Japan; ${ }^{6}$ Department of Urology, Harasanshinn Hospital, Fukuoka, Japan; ${ }^{7}$ Department of Urology, Graduate School of Medicine, Osaka University, Suita, Japan and ${ }^{8}$ Kawasaki, Japan

Correspondence: Dr Y Sato, Department of Human Genetics and Public Health, Graduate School of Medical Science, University of Tokushima, 3-18-15 Kuramoto-cho, Tokushima City 770-8503 Japan.

E-mail: sato@ph.tokushima-u.ac.jp

Received 20 December 2011; revised 22 March 2012; accepted 26 March 2012; published online 26 April 2012
} 


\section{MATERIALS AND METHODS}

\section{Subjects}

From 1997 to 2002, we performed a survey of the sperm characteristics of the partners of pregnant women in four cities in Japan (order of these cities from north to south: Sapporo, Kanazawa, Osaka and Fukuoka). The male partners of pregnant women who attended obstetric clinics during that period were invited to participate in the study. The eligibility criteria for the male participants were as follows: being aged 20-45 years at the time of the invitation and being a resident of the locality surrounding the hospital at which they were recruited. Both the men and their pregnant partners completed a similar questionnaire to that used in a previous European study. ${ }^{13}$ As a result, 764 participants provided blood and semen samples in addition to answering the abovementioned questionnaire. This study was approved by the ethics committees of the University of Tokushima and St Marianna Medical University. All participants provided informed consent.

\section{Semen analysis}

All of the participating partners of pregnant women were asked to abstain from ejaculation for a period of at least $48 \mathrm{~h}$. Semen samples were obtained once by masturbation and were ejaculated into clean wide-necked sterile non-toxic collection containers. The samples were protected from extremes of temperature and then liquefied at $37^{\circ} \mathrm{C}$ before their examination. The sperm concentration of each sample was assessed using a Neubauer or Bürker-Türk hemocytometer (Erma, Tokyo, Japan) as a counting chamber according to the findings of an external quality control study performed by the Copenhagen center as a reference laboratory. ${ }^{14}$ The results of the internal quality control were analyzed, and the inter-technician correlation coefficient was calculated to be 0.9856; therefore, no correction was undertaken for this potential confounder.

\section{Y chromosome haplotyping}

A total of 12 bi-allelic Y-chromosome markers, RPS4Y (C41T); YAP (599Alu +); M174 (T219C); 12f2.2 (TaqI/10-kb); M213 (UTYintron4b, T290C); M9 (C68G); LLY22g (HindIII (+), A ( -), C); M95 (C172T); SRY + 465 (C52T); 47z (G291C); M122 (T73C); and M134 (54 delG), were typed by the PCR-restriction fragment length polymorphism method and denaturing high performance liquid chromatography. ${ }^{15,16}$ In this system, Y haplogroups were defined according to the nomenclature of the YCC. ${ }^{1}$ In a previous report, it was found that the $12 \mathrm{f} 2.2$ and M125 markers belong to the same lineage. ${ }^{17}$ Our data analysis produced the same results (data not shown). Therefore, we considered the $12 \mathrm{f} 2.2$ allele to represent the D2al lineage (Figure 1).

\section{Statistical analysis}

To estimate the haplogroup diversity among the cities, pairwise $F_{\mathrm{ST}}$ values were calculated using ARLEQUIN version 3.5. ${ }^{18}$ Comparisons between birth month and haplogroup frequencies were carried out using the $\chi^{2}$ test. The sperm concentration analyses were processed using log-transformed values. The

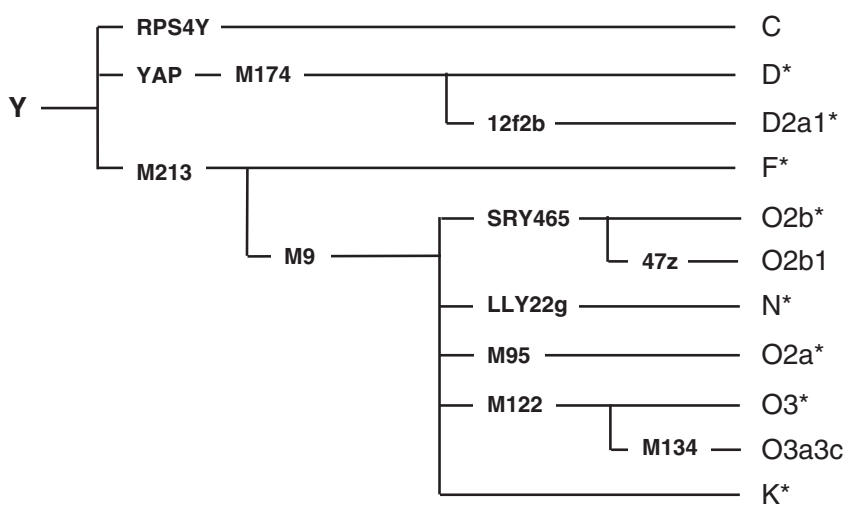

Figure 1 Phylogenetic tree constructed with the $12 \mathrm{Y}$ chromosome binary markers. unpaired $t$-test or one-way ANOVA followed by Fisher's least significant difference test was used to statistically analyze the relationships between mean sperm concentrations and haplogroup or ejaculation month. All statistical analyses were performed using SPSS version 20.0 (SPSS, Inc., Chicago, IL, USA), and statistical significance was indicated by $P$ values of $<0.05$.

\section{RESULTS AND DISCUSSION}

In this study, we hypothesized that the genetic background of Japanese males might have a role in the seasonal variations in their sperm concentrations and that these variations might affect their reproductive abilities, and hence, have contributed to shaping the modern population of Japan. To test this hypothesis, we used DNA samples from 764 Japanese male partners of pregnant women, who were recruited between 1997 and 2002 in four cities, to type their Y chromosome polymorphisms and investigate the seasonal variations in their sperm concentrations, and the relationships between these variations and the different Japanese $\mathrm{Y}$ chromosome lineages.

Various Y chromosome loci were typed, and several haplogroups were determined among the studied samples according to the YCC criteria. ${ }^{1}$ The participating males belonged to the following $\mathrm{Y}$ chromosome haplogroups: C $(13.6 \%), \mathrm{D}^{\star}(14.8 \%), \mathrm{D} 2 \mathrm{a} 1 \mathrm{(17.1 \% )}$, $\mathrm{O}_{2} \mathrm{~b}^{*}(9.0 \%), \mathrm{O} 2 \mathrm{~b} 1$ (19.8\%), O3* $(10.7 \%)$ and O3a3c (9.3\%), and O2b1 was the most dominant haplogroup (Table 1). It remains unclear why O2b1 is dominant in Japan; however, O2b1 males represent a minority in the Korean Peninsula. ${ }^{7}$ Summaries of the haplogroup frequency data and birth month distribution in each city are shown in Supplementary Tables 1 and 2. In order to determine the patterns of variation among each city, we calculated population pairwise $F_{\mathrm{ST}}$ genetic distances, but no significant differences were detected (Supplementary Table 3 ).

Table 1 shows the distribution of the male participants' birth months according to their Y haplogroups. Figure 2 shows a stacked area chart of the frequency data shown in Table 1. We do not believe that the data was affected by bias as we selected the participants based solely on whether their partners were pregnant.

The number of births of males belonging to haplogroups $C$ and $\mathrm{D}^{*} / \mathrm{D} 2 \mathrm{a} 1$ peaked in April and February, respectively. On the other hand, the births of males from haplogroups $\mathrm{O} 2 \mathrm{~b} 1, \mathrm{O}^{*}$ and $\mathrm{O} 3 \mathrm{a} 3 \mathrm{c}$ peaked in September, and those of males belonging to haplogroup $\mathrm{O}_{2} \mathrm{~b}^{\star}$ peaked in June. From January to June, D2a1 males accounted for most births in 4 out of the 6 months (except March and April), and haplogroup $\mathrm{D}^{\star}$ was dominant in April. The O2b1 group was most dominant from July through December, as well as in March. There was a marked decrease in $\mathrm{O} 2 \mathrm{~b} 1$ births in June. Miura ${ }^{19}$ reported that a decrease in the birth rate in June is a characteristic of the Japanese. The birth month frequencies of the haplogroup D2a1 males were higher in the first half of the year (January to June) and lower in the last half of the year (July to December) than those of the O2b1 males ( $\chi^{2}$ test: $\left.P=0.039\right)$.

The mean sperm concentration of the participants was $107.2 \times$ $10^{6} \pm 3.6 \mathrm{ml}^{-1}$ (mean \pm s.e.m.), and no relationship between the mean sperm concentration and age or city was detected by Pearson's correlation coefficient or ANOVA. Figure 3 shows the mean sperm concentrations of the haplogroup $\mathrm{C}, \mathrm{D}^{*}, \mathrm{D} 2 \mathrm{a} 1$ and $\mathrm{O} 2 \mathrm{~b} 1$ males in each month. These four groups included over 100 individuals, and at least four participants were assessed in each month. The sperm concentrations of the haplogroup $\mathrm{D}^{\star}$ males were significantly higher than those of the C, D2a1 and O2b1 males $(P<0.05)$ in January, and those of the D2al males were significantly higher than those of the $C$, $\mathrm{D}^{*}$ and $\mathrm{O} 2 \mathrm{~b} 1$ males $(P<0.05)$ in June. The haplogroup $\mathrm{C}, \mathrm{D}^{*}$ and D2al males tended to display lower sperm concentrations from 
Table 1 Distribution of the participants' birth months according to their haplogroups

\begin{tabular}{|c|c|c|c|c|c|c|c|c|c|c|c|c|c|}
\hline Haplogroup & January & February & March & April & May & June & July & August & September & October & November & December & Total \\
\hline C & $\begin{array}{r}6 \\
(9.4)\end{array}$ & $\begin{array}{r}9 \\
(12.7)\end{array}$ & $\begin{array}{c}8 \\
(11.4)\end{array}$ & $\begin{array}{c}16 \\
(21.6)\end{array}$ & $\begin{array}{c}8 \\
(14.3)\end{array}$ & $\begin{array}{c}7 \\
(13.0)\end{array}$ & $\begin{array}{c}8 \\
(13.6)\end{array}$ & $\begin{array}{r}4 \\
(6.5)\end{array}$ & $\begin{array}{r}10 \\
(12.7)\end{array}$ & $\begin{array}{c}8 \\
(12.7)\end{array}$ & $\begin{array}{r}10 \\
(17.5)\end{array}$ & $\begin{array}{r}10 \\
(18.2)\end{array}$ & $\begin{array}{c}104 \\
(13.6)\end{array}$ \\
\hline$D^{*}$ & $\begin{array}{r}6 \\
(9.4)\end{array}$ & $\begin{array}{r}12 \\
(16.9)\end{array}$ & $\begin{array}{c}10 \\
(14.3)\end{array}$ & $\begin{array}{c}18 \\
(24.3)\end{array}$ & $\begin{array}{r}5 \\
(8.9)\end{array}$ & $\begin{array}{c}8 \\
(14.8)\end{array}$ & $\begin{array}{c}7 \\
(11.9)\end{array}$ & $\begin{array}{c}9 \\
(14.5)\end{array}$ & $\begin{array}{r}11 \\
(13.9)\end{array}$ & $\begin{array}{r}9 \\
(14.3)\end{array}$ & $\begin{array}{r}8 \\
(14.0)\end{array}$ & $\begin{array}{r}10 \\
(18.2)\end{array}$ & $\begin{array}{c}113 \\
(14.8)\end{array}$ \\
\hline D2a1 & $\begin{array}{c}13 \\
(20.3)\end{array}$ & $\begin{array}{c}15 \\
(21.1)\end{array}$ & $\begin{array}{c}8 \\
(11.4)\end{array}$ & $\begin{array}{c}9 \\
(12.2)\end{array}$ & $\begin{array}{c}12 \\
(21.4)\end{array}$ & $\begin{array}{c}12 \\
(22.2)\end{array}$ & $\begin{array}{c}12 \\
(20.3)\end{array}$ & $\begin{array}{c}14 \\
(22.6)\end{array}$ & $\begin{array}{r}10 \\
(12.7)\end{array}$ & $\begin{array}{c}11 \\
(17.5)\end{array}$ & $\begin{array}{r}8 \\
(14.0)\end{array}$ & $\begin{array}{r}7 \\
(12.7)\end{array}$ & $\begin{array}{c}131 \\
(17.1)\end{array}$ \\
\hline $02 b^{*}$ & $\begin{array}{c}7 \\
(10.9)\end{array}$ & $\begin{array}{c}6 \\
(8.5)\end{array}$ & $\begin{array}{r}6 \\
(8.6)\end{array}$ & $\begin{array}{r}3 \\
(4.1)\end{array}$ & $\begin{array}{c}7 \\
(12.5)\end{array}$ & $\begin{array}{c}9 \\
(16.7)\end{array}$ & $\begin{array}{r}3 \\
(5.1)\end{array}$ & $\begin{array}{c}7 \\
(11.3)\end{array}$ & $(2.5)^{2}$ & $\begin{array}{c}7 \\
(11.1)\end{array}$ & $(8.8)^{5}$ & $\begin{array}{r}7 \\
(12.7)\end{array}$ & $\begin{array}{r}69 \\
(9.0)\end{array}$ \\
\hline 02b1 & $\begin{array}{c}10 \\
(15.6)\end{array}$ & $\begin{array}{r}12 \\
(16.9)\end{array}$ & $\begin{array}{c}15 \\
(21.4)\end{array}$ & $\begin{array}{c}12 \\
(16.2)\end{array}$ & $\begin{array}{c}7 \\
(12.5)\end{array}$ & $\begin{array}{r}5 \\
(9.3)\end{array}$ & $\begin{array}{c}15 \\
(25.4)\end{array}$ & $\begin{array}{c}15 \\
(24.2)\end{array}$ & $\begin{array}{r}21 \\
(26.6)\end{array}$ & $\begin{array}{c}15 \\
(23.8)\end{array}$ & $\begin{array}{r}11 \\
(19.3)\end{array}$ & $\begin{array}{r}13 \\
(23.6)\end{array}$ & $\begin{array}{c}151 \\
(19.8)\end{array}$ \\
\hline 03* & $\begin{array}{c}10 \\
(15.6)\end{array}$ & $\begin{array}{r}7 \\
(9.9)\end{array}$ & $\begin{array}{c}11 \\
(15.7)\end{array}$ & $\begin{array}{r}6 \\
(8.1)\end{array}$ & $\begin{array}{c}9 \\
(16.1)\end{array}$ & $\begin{array}{r}5 \\
(9.3)\end{array}$ & $\begin{array}{r}5 \\
(8.5)\end{array}$ & $\begin{array}{r}5 \\
(8.1)\end{array}$ & $\begin{array}{r}13 \\
(16.5)\end{array}$ & $\begin{array}{r}4 \\
(6.3)\end{array}$ & $\begin{array}{r}6 \\
(10.5)\end{array}$ & $(1.8)^{1}$ & $\begin{array}{c}82 \\
(10.7)\end{array}$ \\
\hline 03a3c & $\begin{array}{c}7 \\
(10.9)\end{array}$ & $\begin{array}{r}3 \\
(4.2)\end{array}$ & $\begin{array}{c}8 \\
(11.4)\end{array}$ & $\begin{array}{c}9 \\
(12.2)\end{array}$ & $\begin{array}{r}5 \\
(8.9)\end{array}$ & $\begin{array}{r}4 \\
(7.4)\end{array}$ & $\begin{array}{r}5 \\
(8.5)\end{array}$ & $\begin{array}{r}5 \\
(8.1)\end{array}$ & $\begin{array}{r}9 \\
(11.4)\end{array}$ & $\begin{array}{r}5 \\
(7.9)\end{array}$ & $\begin{array}{r}7 \\
(12.3)\end{array}$ & $\begin{array}{l}{ }^{4} \\
(7.3)^{4}\end{array}$ & $\begin{array}{r}71 \\
(9.3)\end{array}$ \\
\hline Other & $\begin{array}{r}5 \\
(7.8)\end{array}$ & $\begin{array}{r}7 \\
(9.9)\end{array}$ & $\begin{array}{r}4 \\
(5.7)\end{array}$ & $\begin{array}{c}1 \\
(1.4)\end{array}$ & $\begin{array}{r}3 \\
(5.4)\end{array}$ & $\begin{array}{r}4 \\
(7.4)\end{array}$ & $\begin{array}{r}4 \\
(6.8)\end{array}$ & $\begin{array}{r}3 \\
(4.8)\end{array}$ & $(3.8)^{3}$ & $\begin{array}{r}4 \\
(6.3)\end{array}$ & $(3.5)^{2}$ & $\begin{array}{l}3 \\
(5.5)\end{array}$ & $\begin{array}{r}43 \\
(5.6)\end{array}$ \\
\hline Total & 64 & 71 & 70 & 74 & 56 & 54 & 59 & 62 & 79 & 63 & 57 & 55 & 764 \\
\hline
\end{tabular}

The numbers indicate the individuals who were born in each month. The gray boxes indicate the most dominant group in each month. Bold letters indicate the most dominant months for each haplogroup. The numbers in parentheses indicate frequency (\%).

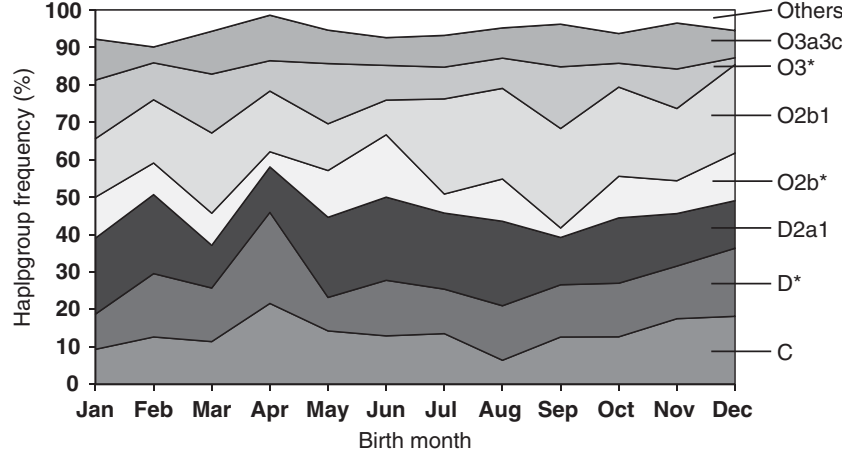

Figure 2 Stacked area chart of the data shown in Table 1.

March to May, but their sperm concentrations started to increase from June or July. In addition, the sperm concentrations of the haplogroup $\mathrm{O} 2 \mathrm{~b} 1$ and $\mathrm{D}^{\star}$ males significantly decreased from July to August, and from January to February, respectively $(P<0.05)$. In contrast, the $\mathrm{O} 2 \mathrm{~b} 1 \mathrm{males}$ tended to display higher sperm concentrations in the first half of the year followed by a sudden decrease in their sperm concentrations from July to August $(P<0.05)$. Most males experience sperm reductions once or twice a year. As the basal level of an individual's sperm concentration can vary significantly within a year, we cannot determine if a male is in a normal or reduced phase based on a single sperm count. Therefore, we examined the variation in the mean sperm concentration. Assuming that male fertility is correlated with sperm concentration, the tendency for the sperm concentrations of the haplogroup $\mathrm{C}$ and $\mathrm{D}^{*}$ males to increase from May to June matches their high birth rate in April. In addition, the tendency for the sperm concentration of the D2al males to decrease from May to June and increase from June to July/August matches their low birth rate in March and April and their high birth rate in May and June. In addition, the decreasing the sperm concentrations of the $\mathrm{O} 2 \mathrm{~b} 1$ males in July to August explain their low birth rate in June.

Seasonal variations in the conception rate of human beings and the number of births have been described previously. ${ }^{20}$ Initial studies have

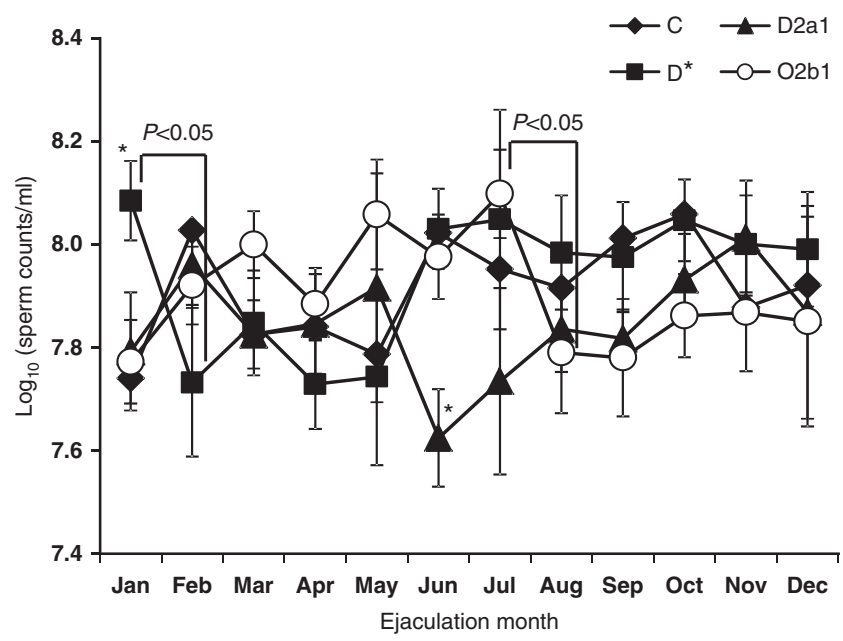

Figure 3 Mean sperm concentrations of the haplogroup C, D*, D2a1 and 02b1 males. Mean values were calculated after logarithmic transformation of the data. Statistically significant differences among these four groups were only detected in January and June $\left({ }^{*} P<0.05\right.$, with one-way ANOVA). Differences between the seasonal changes within a haplogroup were only detected from January to February in haplogroup $D^{*}$ and from July to August in the haplogroup 02b1 $(P<0.05)$. Data are expressed as mean \pm s.e.m. values.

attributed the variations in semen parameters during the year to climatic differences. The high temperatures experienced in summer were considered to be responsible for the reduction in semen quality observed during this season, whereas the lower temperatures of the winter months were thought to favor spermatogenesis. ${ }^{21,22}$ However, subsequent studies have found that other factors besides temperature are involved in the seasonal variations in sperm quality; for example, the amount of daylight. ${ }^{23,24}$ The Japanese monkey, the northernmost primate and the only non-human primate in Japan that displays a clear seasonal breeding pattern, bears offspring in spring. On the other hand, seasonal breeding is rarely seen in higher primates in the Torrid Zone. It remains unclear whether humans breed seasonally in nature. 
The seasonal variations in semen parameters differ according to population and country. For example, the sperm concentration in the Chongqing area of southwest China was significantly low in summer (June) ${ }^{25}$; on the other hand, military personnel from the People's Republic of China displayed significantly low values in autumn (September, October). ${ }^{26}$ These differences might have been due to demographic characteristics, lifestyle factors, environmental factors or genetic variation; however, this needs to be clarified in future. In the present study, we showed that the sperm concentrations in January and June differ within $\mathrm{Y}$ chromosome haplogroups. The abovementioned differences in China might also have been linked to $\mathrm{Y}$ chromosome haplogroup differences.

In a previous study, we showed that the spermatogenic ability of Japanese males differs among $\mathrm{Y}$ chromosome lineages. ${ }^{10}$ The $\mathrm{Y}$ chromosome is essential for spermatogenesis. Deletions in azoospermia factor regions $\mathrm{a}, \mathrm{b}$ and $\mathrm{c}$ on the long arm of the $\mathrm{Y}$ chromosome result in spermatogenic failure and severely reduce sperm concentrations. ${ }^{27,28}$ However, the associations between partial deletions of azoospermia factor region c; that is, gr/gr, g1/g3 and b2/b4, and spermatogenic failure differ according to population and country. Sin et al. ${ }^{29}$ found that there were no significant differences in the frequency of gr/gr deletions between their infertile and control groups, and gr/gr deletions were widespread in haplogroup D. $\mathrm{Y}$ chromosome lineage might be heavily involved in spermatogenesis.

In summary, we detected differences between the birth month distributions and sperm concentrations of various $\mathrm{Y}$ chromosomal haplogroups in Japan. This phenomenon might have resulted from seasonal variations in sperm production, which is controlled by the $\mathrm{Y}$ chromosome.

\section{ACKNOWLEDGEMENTS}

This study was supported by the Ministry of Health and Welfare of Japan (1013201) and the European Union (BMH4-CT96-0314). We thank all the volunteers who participated in this study. We are grateful to Miss Yukiko Unemi, Keiko Tsuji and Mr Kensuke Sasaki for their excellent technical assistance.

1 Karafet, T. M., Mendez, F. L., Meilerman, M. B., Underhill, P. A., Zegura, S. L. \& Hammer, M. F. New binary polymorphisms reshape and increase resolution of the human Y chromosomal haplogroup tree. Genome. Res. 18, 830-838 (2008).

2 Zhong, H., Shi, H., Qi, X. B., Xiao, C. J., Jin, L., Ma, R. Z. et al. Global distribution of Y-chromosome haplogroup $\mathrm{C}$ reveals the prehistoric migration routes of African exodus and early settlement in East Asia. J. Hum. Genet. 55, 428-435 (2010).

3 Hammer, M. F. \& Horai, S. Y chromosomal DNA variation and the peopling of Japan. Am. J. Hum. Genet. 56, 951-962 (1995).

4 Tajima, A., Hayami, M., Tokunaga, K., Juji, T., Matsuo, M., Marzuki, S. et al. Genetic origins of the Ainu inferred from combined DNA analyses of maternal and paternal lineages. J. Hum. Genet. 49, 187-193 (2004).

5 Hammer, M. F., Karafet, T. M., Park, H., Omoto, K., Harihara, S., Stoneking, M. et al. Dual origins of the Japanese: common ground for hunter-gatherer and farmer $Y$ chromosomes. J. Hum. Genet. 51, 47-58 (2006).

6 Wen, B., Li, H., Lu, D., Song, X., Zhang, F., He, Y. et al. Genetic evidence supports demic diffusion of Han culture. Nature 431, 302-305 (2004).
7 Jin, H. J., Kwak, K. D., Hammer, M. F., Nakahori, Y., Shinka, T., Lee, J. W. et al. Y-chromosomal DNA haplogroups and their implications for the dual origins of the Koreans. Hum. Genet. 114, 27-35 (2003).

8 Nakagome, Y., Young, S. R., Akane, A., Numabe, H., Jin, D. K., Yamori, Y. et al. A Y-associated allele may be characteristic of certain ethnic groups in Asia. Ann. Hum. Genet. 56, 311-314 (1992).

9 Lin, S. J., Tanaka, K., Leonard, W., Gerelsaikhan, T., Dashnyam, B., Nyamkhishig, S. et al. A Y-associated allele is shared among a few ethnic groups of Asia. Jpn. J. Hum. Genet. 39, 299-304 (1994).

10 Kuroki, Y. Iwamoto, T., Lee, J., Yoshiike, M. Nozawa, S., Nishida, T et al. Spermatogenic ability is different among males in different $Y$ chromosome lineage. J. Hum. Genet. 44, 289-292 (1999).

11 Krausz, C., Quintana-Murci, L., Rajpert-De Meyts, E., Jørgensen, N., Jobling, M. A et al. Identification of a $Y$ chromosome haplogroup associated with reduced sperm counts. Hum. Mol. Genet. 10, 1873-1877 (2001).

12 Baba, K., Nishida, T., Yoshiike, M., Nozawa, S., Hoshino, T. \& Iwamoto, T. Current status of reproductive function in Japanese fertile men: international collaborative project on a study of partners of pregnant women. Int. J. Androl. 23(Suppl 2) 54-56 (2000).

13 Jørgensen, N., Andersen, A. G., Eustache, F., Irvine, D., Suominen, J. S. S., Petersen, J. H. et al. Regional differences in semen quality in Europe. Hum. Reprod. 16

$1012-1019$ (2001)

14 Iwamoto, T., Nozawa, S., Yoshiike, M. Hoshino, T., Baba, K. Matsushita, T. et al. Semen quality of 324 fertile Japanese men. Hum. Reprod. 21, 760-765 (2006).

15 Su, B., Xiao, C., Deka, R., Seielstad, M. T., Kangwanpong, D., Xiao, J. et al. Y chromosome haplotypes reveal prehistorical migrations to the Himalayas. Hum. Genet. 107, 582-590 (2000).

16 Underhill, P. A., Passarino, G., Lin, A. A., Shen, P., Mirazon Lahr, M. et al. The phylogeography of $Y$ chromosome binary haplotypes and the origins of modern human populations. Ann. Hum. Genet. 65, 43-62 (2001).

17 de Carvalho, C. M., Zuccherato, L. W., Fujisawa, M., Shirakawa, T., Riberio-dos-Santos, A. K., Santos, S. E. et al. Study of AZFc partial deletion gr/gr in fertile and infertile Japanese males. J. Hum. Genet. 51, 794-799 (2006).

18 Excoffier, L. \& Lischer, H. E. Arlequin suite ver 3.5: a new series of programs to perform population genetics analyses under Linux and Windows. Mol. Ecol. Resour. 10, 564-567 (2010)

19 Miura, T. The influence of seasonal atmospheric factors on human reproduction. Experimentia 43, 48-54 (1987).

20 Janett, F., Thun, R., Niederer, K., Burger, D. \& Hässig, M. Seasonal changes in semen quality and freezability in the warmblood stallion. Theriogenology $60,453-461$ (2003)

21 Levine, R. J., Bordson, B. L., Mathew, R. M., Brown, M. H., Stanley, J. M. \& Star, T. B. Deterioration of semen quality during summer in New Orleans. Fertil. Steril. 49, 900907 (1988).

22 Politoff, L., Birkhauser, M., Almendral, A. \& Zorn, A. New data confirming a circannual rhythm in spermatogenesis. Fertil. Steril. 52, 486-489 (1989).

23 Snyder, P. J. Fewer sperm in the summer-it's not the heat, it's.... N. Engl. J. Med. 323, 54-56 (1990)

24 Levine, R. J., Brown, M. H., Bell, M., Shue, F., Greenberg, G. N. \& Bordson, B. L. Air-conditioned environments do not prevent deterioration of human semen quality during the summer. Fertil. Steril. 57, 1075-1083 (1992).

25 Li, Y., Lin, H., Ma, M., Li, L., Cai, M., Zhou, N. et al. Semen quality of 1346 healthy men, results from the Chongqing area of southwest China. Hum. Reprod. 24, 459-469 2009).

26 Zou, Z., Hu, H., Song, M., Shen, Y., Guo, X., McElreavey, K. et al. Semen quality analysis of military personnel from six geographical areas of People's Republic of China. Fertil. Steril. 95, 2018-2023 (2011).

$27 \mathrm{Ma}$, K., Sharkey, A., Kirsch, S., Vogt, P., Keil, R., Hargreave, T. B. et al. Towards the molecular localization of the AZF locus: mapping of microdeletions in azoospermic men within 14 subintervals of interval 6 of the human Y chromosome. Hum. Mol. Genet 1, 29-33 (1992).

28 Vogt, P., Chandley, A. C., Hargreave, T. B., Keil, R., Ma, K. \& Sharkey, A Microdeletions in interval 6 of the $Y$ chromosome of males with idiopathic sterility point to disruption of AZF, a human spermatogenesis gene. Hum. Genet. 89, 491-496 (1992)

29 Sin, H. S., Koh, E., Shigehara, K., Sugimoto, K., Maeda, Y., Yoshida, A. et al. Features of constitutive gr/gr deletion in a Japanese population. Hum. Reprod. 25, 2396-2403 (2010).

Supplementary Information accompanies the paper on Journal of Human Genetics website (http://www.nature.com/jhg) 